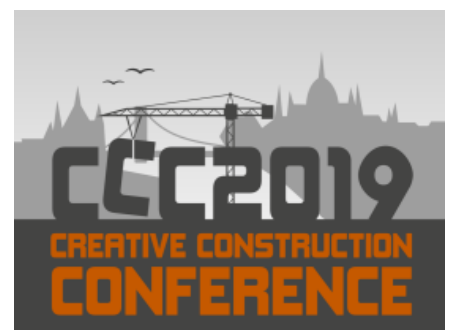

Available online at 2019.creative-construction-conference.com/proceedings/

CCC 2019

Proceedings of the Creative Construction Conference (2019) 095

Edited by: Miroslaw J. Skibniewski \& Miklos Hajdu

https://doi.org/10.3311/CCC2019-095

Creative Construction Conference 2019, CCC 2019, 29 June - 2 July 2019, Budapest, Hungary

\title{
Employing generative design for sustainable construction
}

\author{
Hussein Abdallah ${ }^{\mathrm{a}}$, Farah Ezzedine ${ }^{\mathrm{b}}$, Angela Haddad ${ }^{\mathrm{b}}$, Ghadeer Salami $^{\mathrm{b}}$, Hala Sanboskani ${ }^{\mathrm{b}}$, \\ Mayssa Dabaghic ${ }^{\mathrm{c}}$, Farook Hamzeh ${ }^{\mathrm{c} *}$ \\ ${ }^{a}$ General Manager, United General Holding, Beirut 25-5149, Lebanon \\ ${ }^{b}$ Graduate Student, American University of Beirut, Beirut 1107-2020, Lebanon \\ ${ }^{c}$ Assistant Professor, American University of Beirut, Beirut 1107-2020, Lebanon
}

\begin{abstract}
Generative design is the alteration of an object's shape to optimize its function. Currently, the scope of generative design is limited in the structural civil engineering field. Structural design still follows conventional methods compatible with conventional construction processes. These processes restrict the flexibility in design resulting in structural elements having excess materials to satisfy critical structural capacity requirements. This introduces additional costs and higher environmental impacts. New tools, such as concrete and steel 3D printers, are emerging to enable more complex geometries in construction allowing higher flexibility in design options. Inspired by the above, this paper aims at developing a design engine that provides optimal design solutions to reinforced concrete beams with sufficient structural capacities while using less materials and resources. Based on ACI code design guidelines, a cantilever beam was structurally analyzed to relate geometry parameters to structural capacity. Optimization was achieved by minimizing the depth and the steel reinforcement ratio at each segment along its length. Hence, concrete and steel at each location would take their optimal quantities. This results in lighter and more economic structures conforming to the structural capacities required by the codes. The engine is based on three objective functions that solve for the minimum values of beam depth and reinforcement at each section which optimize cost and $\mathrm{CO}_{2}$ emissions individually or simultaneously. MATLAB was used to design the optimized beam and to calculate the percentage decrease in cost and $\mathrm{CO}_{2}$ emissions between the optimized and conventional beam. A significant reduction ranging between $40 \%$ and $52 \%$ of cost and between $39 \%$ and $51 \%$ of $\mathrm{CO}_{2}$ emissions per beam is achieved. If the design engine developed was utilized in parallel with the 3D printing construction method, structures with optimized quantities, materials, and shapes would be developed. Thus, minimizing drastic effects on the environment and achieving reduced costs.
\end{abstract}

(C) 2019 The Authors. Published by Budapest University of Technology and Economics \& Diamond Congress Ltd.

Peer-review under responsibility of the scientific committee of the Creative Construction Conference 2019.

Keywords: $3 D$ printing construction method; $\mathrm{CO}_{2}$ emissions optimization; cost optimization; generative design; structural analysis

\section{Introduction}

Generative design is being addressed in the automotive and architectural fields by changing an element's shape to optimize its function. However, the structural engineering field lags in this area where structural engineers continue to use methods established approximately 100 years ago [1,2]. Generative design systems aim to create design processes that produce more efficient shapes by exploiting current computing and manufacturing capabilities [3]. Such systems are inspired from nature by accepting and rejecting design options to get a form that uses precise amounts of materials

* Corresponding author: Author email: fh35@aub.edu.lb 
Hussein Abdallah, et al. / Proceedings of the Creative Construction Conference (2019) 095 https://doi.org/10.3311/CCC2019-095

where required, to eventually create optimized structures that meet or exceed traditional capabilities [4]. Similar processes of imitating nature's strategies are called biomimicry [5].

Optimization approaches with defined objectives and constraints are employed through computer algorithms to achieve such structural improvements [6]. Optimization techniques fall into three categories: mathematical, optimality, and heuristic programming methods, each of which has its applications and limitations [6].

With the quick advancement in 3D printing technologies, shape optimization has become the interest of not only manufacturers but also anyone who has access to a 3D printer [7]. One of the main advantages that concrete 3D printing provides over the conventional construction method is that the concrete does not need an existing formwork [8]. In fact, optimized concrete structures are best constructed using 3D printing technology where the designed geometry meets structural requirements while consuming the least possible construction resources [7]. As for steel 3D printing, Arc welding is considered the most efficient additive manufacturing technique [9]. These methods are mainly entitled to push the boundaries and constraints of the design world that are available for engineers and architects [8].

This research aims at generating an optimized structural element (singly reinforced cantilever beam) by reducing materials' quantities; thus, reducing its environmental footprint and cost. The scope was set to develop an engine that provides optimal design solutions to reinforced concrete beams having sufficient structural capacities and utilizing fewer resources. The variables studied are the depth of concrete and the steel reinforcement ratio. Moreover, employing $3 \mathrm{D}$ printing for the construction process in such context was examined.

To achieve the study objectives, an optimization process was applied to a cantilever beam to explore its effects on design parameters and consequently cost and $\mathrm{CO}_{2}$ emissions. For comparison purposes, the implications were checked for a non-optimized cantilever beam.

\section{Methodology}

The project is divided into two parts: developing a design engine and evaluating the 3D printing construction process. To develop the design engine, the following methodology was adopted: defining the design variables, performing theoretical structural analysis, building the engine through MATLAB coding, and realizing the outputs.

\subsection{Problem description and design steps}

Two cantilever beams were studied. The first is the reference beam, which is designed by the traditional methods, while the second is the beam with varying cross section, which is designed considering optimization techniques as shown in Fig. 1 (a) and Fig. 1 (b) respectively.

Focusing on the optimized beam design, the structure was analysed by basic flexural design methods to determine the required concrete depth $h$ and steel reinforcement ratio at each section (considering a uniform incremental length $x$ across the entire length $L$ as presented in Fig. 1 (b)). Shear design was performed to determine the area of shear reinforcement needed for each region. Deflection checks based on maximum permissible deflections suggested in Table 9.5 (b) in the ACI code were conducted [10]. Long term deflection is reduced by adding compressive steel [10]; however, after checking deflection, it was realized that there is no need to add compressive steel.

The study considers a singly reinforced cantilever beam with varying depth $h(\mathrm{~m})$ and steel reinforcement ratio $\rho$ as shown in Fig. 1 (b).

a

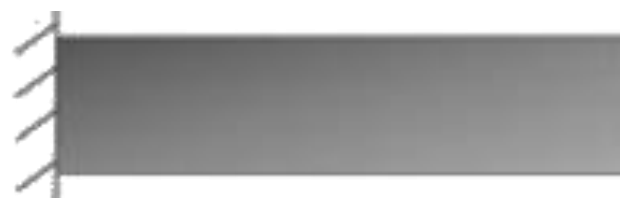

b

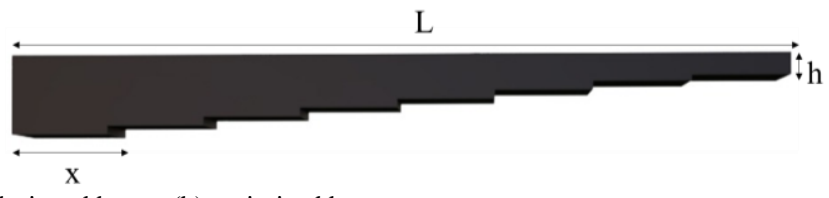

Fig. 1. (a) traditionally designed beam; (b) optimized beam. 
Hussein Abdallah, et al. / Proceedings of the Creative Construction Conference (2019) 095 https://doi.org/10.3311/CCC2019-095

The length $L(\mathrm{~m})$ and width $b(\mathrm{~m})$ of the beam are user defined parameters. The structure is subjected to a uniformly applied load including superimposed dead load $S D L$, live load $L L$ and self-weight of the beam. The total dead load $D L$ is the sum of the $S D L$ and self-weight. Based on typical applications, the considered $S D L$ and $L L$ are $200\left(\mathrm{~kg} / \mathrm{m}^{2}\right)$ and $250\left(\mathrm{~kg} / \mathrm{m}^{2}\right)$ respectively. The load combination employed is $1.2 \times D L+1.6 \times L L$ [10]; however, since the self-weight is varying along the length of the beam the constant distributed load $C(\mathrm{~kg} / \mathrm{m})$, excluding self-weight, would be as calculated in (1).

$$
C=T A \times(1.2 \times S D L+1.6 \times L L)
$$

The corresponding ultimate design loads: bending moment $M_{u}$ and shear force $V_{u}$ acting on the critical section of the beam were calculated. A sample equation for a beam divided into two sections is shown in (2) and (3).

$$
\begin{aligned}
& M_{u(2)=} \frac{1}{2} C\left[x_{(1)}+x_{(2)}\right]^{2}+\gamma b\left(h_{(1)}\right)\left(x_{(1)}\right)\left(x_{(2)}+\frac{x_{(1)}}{2}\right)+\gamma b\left(h_{(2)}\right)\left(x_{(2)}\right)\left(\frac{x_{(2)}}{2}\right) \\
& V_{u(2)=}\left[C+1.2 \gamma b\left(h_{(2)}\right)\right]
\end{aligned}
$$

Where $x_{(1)}, h_{(1)}, x_{(2)}$ and $h_{(2)}$ represent the length and depths of sections one and two respectively. All remaining variables and parameters mentioned in (2) and (3) in addition to other parameters are described in Table 1.

\subsection{Design variables and parameters}

The design variables are the beam depth and the ratio of steel reinforcement. The parameters that are set as inputs into the code include: $L, b$, increment length $x$, and $T A$. Table 1 includes all the design parameters, defined as constants during the optimization process. The values are those used by common reinforced concrete design practice or as depicted by the ACI code [10]. Also, Table 1 includes the necessary design equations used to calculate parameters

\begin{tabular}{|c|c|c|c|}
\hline Parameter & Value & Parameter & Equation \\
\hline Concrete compressive strength & $f_{c}^{\prime}=280 \times 10^{4}\left(\mathrm{~kg} / \mathrm{m}^{2}\right)$ & Effective depth of the beam & $d=h-0.05(\mathrm{~m})$ \\
\hline Reinforcement yield strength & $f_{y}=4200 \times 10^{4}\left(\mathrm{~kg} / \mathrm{m}^{2}\right)$ & Area of flexural steel reinforcement & $A_{s}=\rho \times b \times d\left(\mathrm{~m}^{2}\right)$ \\
\hline $\begin{array}{l}\text { Specific mass of reinforced } \\
\text { concrete }\end{array}$ & $\gamma=2500\left(\mathrm{~kg} / \mathrm{m}^{3}\right)$ & Nominal moment capacity & $\begin{array}{l}M_{n}=A_{S} \times f_{y} \times\left(d-\frac{\rho \times(h-0.05) \times f_{y}}{2 \times 0.85 \times f_{c}^{\prime}}\right) \\
(\mathrm{kg} . \mathrm{m})\end{array}$ \\
\hline Specific mass of steel & $\mathcal{L}_{s}=7.8 \times 1000\left(\mathrm{~kg} / \mathrm{m}^{3}\right)$ & Spacing of shear reinforcement & $s(\mathrm{~m})$ \\
\hline $\begin{array}{l}\text { Strength reduction factor for } \\
\text { shear }\end{array}$ & $\emptyset=0.75$ & $\begin{array}{l}\text { Nominal shear strength provided by } \\
\text { concrete }\end{array}$ & $V_{c}=2 \sqrt{f_{c}^{\prime}} \times b \times d(\mathrm{~kg})$ \\
\hline \multirow{2}{*}{$\begin{array}{l}\text { Strength reduction factor for } \\
\text { flexure }\end{array}$} & $\varnothing=0.9$ & Nominal shear strength & $V_{n}=\frac{V_{u}}{\varnothing}(\mathrm{kg})$ \\
\hline & $\beta_{1}=0.85$ & $\begin{array}{l}\text { Nominal shear strength provided by } \\
\text { shear reinforcement }\end{array}$ & $V_{s}=V_{n}-V_{c}(\mathrm{~kg})$ \\
\hline Tributary area & $T A(\mathrm{~m})$ & Area of shear reinforcement & $A_{v}=\frac{V_{s}}{d \times f_{y}} \times s\left(\mathrm{~m}^{2}\right)$ \\
\hline Concrete cover & $5 \mathrm{~cm}$ & & \\
\hline
\end{tabular}
referred to in other sections of the paper [10].

Table 1. Design parameters and corresponding values and equations.

\subsection{Optimization problem and solution method}

Two MATLAB optimization solvers were used: "fmincon" and "gamultiobj". "fmincon" function follows the Lagrangian Multiplier Method (mathematical programming method) which is capable of performing optimization for constrained complex engineering problems [11], whereas "gamultiobj" uses a controlled elitist genetic algorithm (heuristic method) that favors fitter individuals [12]. "fmincon" performs constrained nonlinear multi-variable optimization that requires an initial estimate to find a constrained minimum of an objective function [13,14]. Two objective functions were considered separately: one minimizes cost and the other minimizes $\mathrm{CO}_{2}$ emissions to yield 
Hussein Abdallah, et al. / Proceedings of the Creative Construction Conference (2019) 095

https://doi.org/10.3311/CCC2019-095

optimized depth and reinforcement values. Another scenario of considering both objectives simultaneously was also evaluated. Such a scenario is not permissible using Lagrangian optimization, therefore a genetic algorithm which allows multi-objective optimization was used [12].

The objective functions corresponding to the minimization of cost and $\mathrm{CO}_{2}$ emissions are (4) and (5) respectively. Table 2 summarizes cost estimates that are based on common practice in Lebanon, and $\mathrm{CO}_{2}$ emissions in reference to [15].

Table 2. Cost and $\mathrm{CO}_{2}$ footprint of concrete and reinforcing steel.

\begin{tabular}{llll}
\hline Material & \multicolumn{1}{c}{ Cost } & \multicolumn{1}{c}{$\mathrm{CO}_{2}$} & Quantity \\
\hline Concrete $\left(f c^{\prime}=40 \mathrm{MPa}\right)$ & $80\left(\$ / \mathrm{m}^{3}\right)$ & $518.23\left(\mathrm{~kg} / \mathrm{m}^{3}\right)$ & $b \times h \times$ increment $\left(\mathrm{m}^{3}\right)$ \\
Steel & $600(\$ /$ ton $)$ & $7.4 \times 1000(\mathrm{~kg} /$ ton $)$ & $\alpha_{s} \times \rho \times b \times d \times$ increment (ton) \\
\hline
\end{tabular}

$$
\begin{aligned}
& f_{1}=\left(\text { Cost }_{c} \times \text { Volume }_{c}\right)+\left(\text { Cost }_{s} \times \text { Mass }_{s}\right) \\
& f_{2}=\left(\left(\mathrm{CO}_{2}\right)_{c} \times \text { Volume }_{c}\right)+\left(\left(\mathrm{CO}_{2}\right)_{s} \times \text { Mass }_{s}\right)
\end{aligned}
$$

Where subscripts c and s correspond to concrete and steel respectively.

Serviceability and strength constraints based on the ACI code were considered for the optimization process [10]. Serviceability constraints include maximum allowable deflection $(\mathrm{m}): \frac{\mathrm{L}}{480}(6)$. Strength constraints include: flexural strength according to moment capacity (7), minimum and maximum requirements for flexure reinforcements (8), (9), (10) and (11). The minimum height $h_{\min }$ of concrete considers minimum reinforcement and cover. As recommended in [16] the maximum height $h_{\max }$ of concrete is the width multiplied by 2.5 .

$$
\begin{aligned}
\left|M_{u}\right| & <0.9 \times M_{n}(\mathrm{~kg} . \mathrm{m}) ; \forall \text { increments }\left(\frac{x}{L}\right) \\
h_{\text {min }} & =0.1(\mathrm{~m}) \\
h_{\text {max }} & =2.5 \times b(\mathrm{~m}) \\
\rho_{\text {min }} & =\text { minimum of }\left(\frac{3 \times \sqrt{f_{c}^{\prime}}}{f_{y}} \text { or } \frac{200}{f_{y}}\right) \\
\rho_{\text {max }} & =\frac{0.85 \times \beta_{1} \times f_{c}^{\prime}}{f_{y}}\left(\frac{87000}{87000+f_{y}}\right)
\end{aligned}
$$

The variables in these equations were defined in text of section 2.1 and Table 1.

\section{Results of optimal design}

The optimization process was explored for several cantilever beams having varying lengths $L$ and widths $b$ and subject to different loads. Additionally, non-optimized solutions characterized by a constant cross section were obtained for beams with similar parameters for comparison purposes. The results corresponding to a sample structure of a $4(\mathrm{~m})$ long beam having a width $b$ of $0.3(\mathrm{~m})$ and carrying an area of $8\left(\mathrm{~m}^{2}\right)$, will be elaborated in this section. The geometry resulting from the optimization process differed among the different objective functions. In each of these, the depth $h$ and the ratio of reinforcement $\rho$ converged to the optimal solution that minimizes the respective objective functions. Table 3 summarizes the obtained results.

All objective functions considered yield a much lower concrete volume than that obtained through the traditional approach but a higher total mass of steel reinforcement. These optimum results were also associated with a significant lower cost and $\mathrm{CO}_{2}$ footprint. The different total volume and mass are a consequence of different combinations of depth $h$ and ratio of reinforcement $\rho$ at each section to minimize each respective objective function. It can be noticed that the objective function minimizing cost alone results in the least total concrete volume and the largest reinforcement 
Hussein Abdallah, et al. / Proceedings of the Creative Construction Conference (2019) 095 https://doi.org/10.3311/CCC2019-095

mass, while that minimizing the $\mathrm{CO}_{2}$ footprint results in a higher concrete volume but lower reinforcement. Results emerging from the multi-objective function solution compromise the outcomes.

Additionally, as the increment size decreases a more optimized solution is achieved as observed in Table 3 and Fig. 2. For example, the results of the cost objective function improved by $9 \%$ in terms of volume reduction and $23 \%$ in terms of reinforcement mass reduction when the increment size was reduced from $1(\mathrm{~m})$ to $0.01(\mathrm{~m})$. This reduction was also associated with a reduction of cost and $\mathrm{CO}_{2}$ footprint by approximately $25 \%$ each. All the outputs of the optimization process related to the flexure design are represented in Table 3 below for the non-optimum solutions and for each objective function and increment size. Results for shear and deflection were also obtained as a part of this study but are not presented in the table. Fig. 2 below shows the variation of cost and $\mathrm{CO}_{2}$ footprint as the size of the increment increases or as the number of sections that subdivide the beam decreases. A significant reduction in cost and $\mathrm{CO}_{2}$

\begin{tabular}{|c|c|c|c|c|c|c|c|c|c|}
\hline \multirow{2}{*}{\multicolumn{2}{|c|}{ Conventional (Not Optimized) }} & \multicolumn{2}{|c|}{ Depth (m) } & \multicolumn{2}{|c|}{$\begin{array}{l}\text { Reinforcement } \\
\text { Ratio }\end{array}$} & \multirow{3}{*}{$\begin{array}{l}\begin{array}{l}\text { Concrete } \\
\text { Volume }\left(\mathrm{m}^{3}\right)\end{array} \\
0.577 \\
\end{array}$} & \multirow{3}{*}{$\begin{array}{l}\text { Reinforcement } \\
\text { Mass (tons) } \\
0.028 \\
\end{array}$} & \multirow{3}{*}{$\begin{array}{l}\text { \%Cost } \\
\text { Reduction } \\
- \\
\end{array}$} & \multirow{3}{*}{$\begin{array}{l}\% \mathrm{CO}_{2} \\
\text { Reduction } \\
-\end{array}$} \\
\hline & & 0.481 & & 0.007 & & & & & \\
\hline & Objective Function & Edge & Support & Edge & Support & & & & \\
\hline \multirow{3}{*}{1} & Cost & 0.125 & 0.360 & 0.012 & 0.012 & 0.290 & 0.022 & 41.85 & 38.75 \\
\hline & $\mathrm{CO}_{2}$ & 0.141 & 0.428 & 0.008 & 0.008 & 0.340 & 0.017 & 40.19 & 39.86 \\
\hline & Cost $+\mathrm{CO}_{2}$ & 0.142 & 0.421 & 0.008 & 0.008 & 0.327 & 0.018 & 40.76 & 39.71 \\
\hline \multirow{3}{*}{0.5} & Cost & 0.100 & 0.359 & 0.006 & 0.012 & 0.268 & 0.019 & 47.19 & 44.70 \\
\hline & $\mathrm{CO}_{2}$ & 0.100 & 0.427 & 0.006 & 0.008 & 0.312 & 0.015 & 45.78 & 45.72 \\
\hline & Cost $+\mathrm{CO}_{2}$ & 0.100 & 0.370 & 0.006 & 0.008 & 0.286 & 0.017 & 46.73 & 45.28 \\
\hline \multirow{3}{*}{0.25} & Cost & 0.100 & 0.358 & 0.003 & 0.012 & 0.258 & 0.018 & 49.62 & 47.38 \\
\hline & $\mathrm{CO}_{2}$ & 0.100 & 0.426 & 0.003 & 0.008 & 0.299 & 0.014 & 48.29 & 48.36 \\
\hline & Cost $+\mathrm{CO}_{2}$ & 0.100 & 0.395 & 0.003 & 0.008 & 0.279 & 0.016 & 49.05 & 48.04 \\
\hline \multirow{3}{*}{0.1} & Cost & 0.100 & 0.358 & 0.003 & 0.012 & 0.252 & 0.017 & 51.05 & 48.96 \\
\hline & $\mathrm{CO}_{2}$ & 0.100 & 0.426 & 0.003 & 0.008 & 0.292 & 0.014 & 49.78 & 49.91 \\
\hline & Cost $+\mathrm{CO}_{2}$ & 0.102 & 0.359 & 0.003 & 0.008 & 0.271 & 0.015 & 50.54 & 49.58 \\
\hline \multirow{3}{*}{0.05} & Cost & 0.100 & 0.358 & 0.003 & 0.012 & 0.250 & 0.017 & 51.52 & 49.47 \\
\hline & $\mathrm{CO}_{2}$ & 0.100 & 0.426 & 0.003 & 0.008 & 0.289 & 0.014 & 50.27 & 50.42 \\
\hline & Cost $+\mathrm{CO}_{2}$ & 0.100 & 0.392 & 0.003 & 0.008 & 0.264 & 0.016 & 51.17 & 49.95 \\
\hline \multirow{3}{*}{0.01} & Cost & 0.100 & 0.358 & 0.003 & 0.012 & 0.248 & 0.017 & 51.89 & 49.88 \\
\hline & $\mathrm{CO}_{2}$ & 0.100 & 0.425 & 0.003 & 0.008 & 0.287 & 0.013 & 50.66 & 50.83 \\
\hline & Cost $+\mathrm{CO}_{2}$ & 0.100 & 0.405 & 0.003 & 0.008 & 0.264 & 0.015 & 51.49 & 50.40 \\
\hline
\end{tabular}

footprints is achieved ranging between $\$ 23$ and $\$ 30$ and 196 and $257 \mathrm{~kg}$ of $\mathrm{CO}_{2}$ per beam.

Table 3. Design variables of results for optimized and non-optimized solution.

\section{Discussion}

According to Table 3, the optimized beam resulted in a cost decrease that ranged from $40 \%$ to $52 \%$. If this optimization process is applied to all similar beams in a building, its impact would be more tangible. Additionally, if such optimization processes are adopted in the design of other types of structural elements in a building the effect on cost reduction would be substantial. Also Table 3 shows that the $\mathrm{CO}_{2}$ percentage decrease ranged between $39 \%$ and $51 \%$
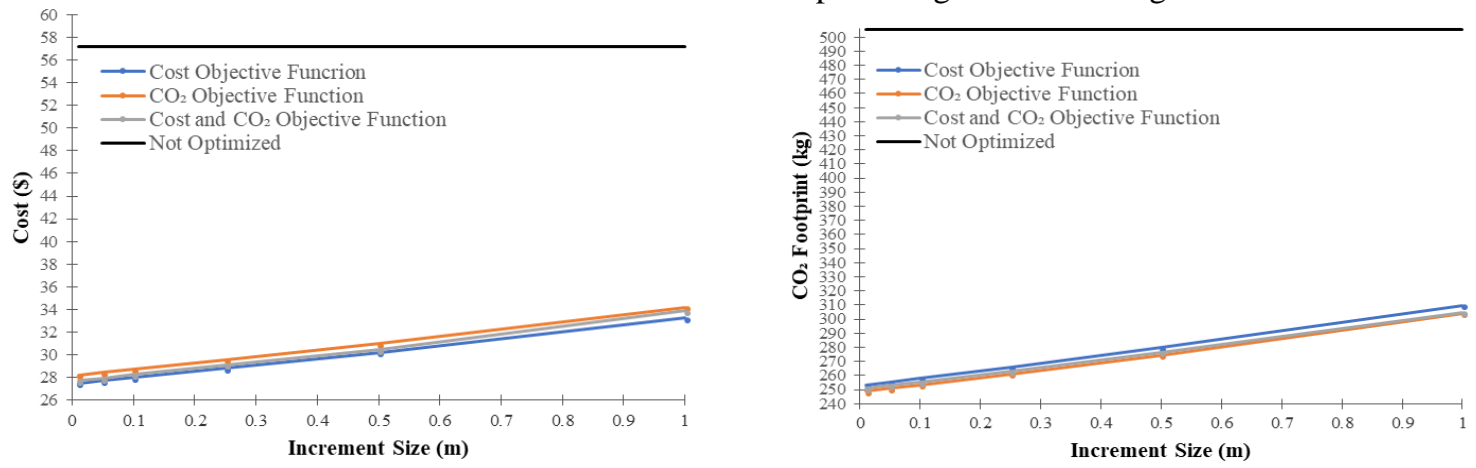

Fig. 2. (a) change in cost with increment size; (b) change in $\mathrm{CO}_{2}$ footprint with increment size. 
Hussein Abdallah, et al. / Proceedings of the Creative Construction Conference (2019) 095 https://doi.org/10.3311/CCC2019-095

using the $\mathrm{CO}_{2}$ objective function. A traditionally designed beam produces around $550 \mathrm{~kg}$ of $\mathrm{CO}_{2}$, whereas an optimized beam can decrease this amount to $249 \mathrm{~kg}$; saving almost $301 \mathrm{~kg}$ of $\mathrm{CO}_{2}$ per cantilever beam. Energy used in cement production accounts for 5\% of the earth's greenhouse emissions [17]. Saving up to $45 \%$ of $\mathrm{CO}_{2}$ emissions in the optimized design represents a significant benefit regarding greenhouse emissions. If the optimized beam was constructed using the conventional construction process, it would be time exhaustive and more complicated for laborers due to the complex beam geometry (Fig. 1 (b)). However, recent construction methods such as concrete and steel 3D printing facilitate the construction of such structures. Thus, the advantages related to time, quality and cost of such method are discussed along with its recent status in the construction industry.

Time is directly correlated with the interest paid to finance the project [18]. According to El Sakka \& Hamzeh, a total of $60 \%$ reduction in construction time can be achieved if 3D printing methods were used [18]. In the conventional process, there is frequent labor movement to transport materials and resources such as forms and steel bars, thus generating waste. However, using 3D printing, such waste is eliminated since it is a form free process [18]. Additionally, due to its form free nature, concrete 3D printing minimizes defects such as honeycombing and segregation [18]. Hence, providing improved quality. Similar concrete defects cannot be addressed until formwork stripping occurs whereas in 3D printing such defects can be addressed in an extruded layer before casting the next one [18]. From a financial perspective, this construction method requires less labor because one 3D printer operator can substitute an entire crew [18]. However, this operator requires a certain set of skills and therefore would have a higher wage than a regular labor [18]. Also, since the construction process requires less time, a significant cut down in salaries and overhead costs would be achieved [18]. Yet, the high cost of concrete printers is a current disadvantage; thus, a thorough study should be performed on the direct cost of a concrete 3D printer to study the life cycle cost of this technology.

\section{Conclusion}

In this study, structural optimization was performed on a RC cantilever beam in order to design low cost and low carbon footprint RC structures. This was achieved by segmenting the beam and minimizing concrete and steel quantities at each section. Primary results yielded cost reduction ranging between $40 \%$ and $52 \%$, while $\mathrm{CO}_{2}$ reduction ranged between $39 \%$ and $51 \%$. Also, considering the construction process, optimized structures can be executed by 3D printing construction methods which are considered to be more efficient and environmentally friendly. Current results seem very promising; a reason for efforts to be exerted to scale this work into entire buildings. Further research can follow this logic into other structural elements to eventually achieve optimized structures, and consequently realize greater economic and environmental advantages.

\section{References}

[1] J. Knippers, "Digital Technologies for Evolutionary Construction," Springer Berlin Heidelberg, pp. 47-54, 2012.

[2] O. Georgiou, P. Richens and P. Shepherd, "Performance based interactive analysis,"," Springer Berlin Heidelberg, pp. 115-122, 2012.

[3] K. Shea, R. Aish and M. Gourtovaia, "Towards integrated performance-driven generative design tools," ELSEVIER, vol. 14, no. 2, pp. 253264, 2005. https://doi.org/10.1016/j.autcon.2004.07.002

[4] A. Sarkhel, "How Autodesk took design inspiration from Nature," Economic Times, September 2016. [Online]. Available: https://tech.economictimes.indiatimes.com/news/internet/how-autodesk-is-using-generative-design-research-to-achieve-new-horizons-in-thedesign-sphere-/54478868. [Accessed April 2018].

[5] B. Institue, "What is biomimicry," Biomimicry Institute, 2018. [Online]. Available: https://biomimicry.org/what-is-biomimicry/. [Accessed April 2018].

[6] S. Ren and S. Galjaard, "Topology Optimisation for Steel Structural Design with Additive Manufacturing," Springer International Publishing Switzerland ,2015. https://doi.org/10.1007/978-3-319-24208-8_3

[7] A. J. Bærentzen, M. Nobel-Jørgensen, N. Aage, O. Sigmund and C. N. Asger, "Combined shape and topology optimization of 3D structures," Elsevier, Denmark, 2014. https://doi.org/ 10.1016/j.cag.2014.09.021

[8] C. Gosselin, R. Duballet, P. Roux, N. Gaudilliere, J. Dirrenberger and P. Morel, "Clément Gosselin, Romain Duballet, Philippe Roux, Nadja Gaudillière, Justin Dirrenberger, Philippe Morel," HAL, 2016.

[9] L.-E. Rannar, A. Glad and C.-G. Gustafon, "Efficient cooling with tool inserts manufactured by electron beam melting," Rapid Prototyping Journal, vol. 13, no. 3, pp. 128-135, 2007. https://doi.org/10.1108/13552540710750870

[10] ACI Committee 318, Building Code Requirements for Structural Concrete (ACI 318-11) and Commentary, Michigan, 2011. 
Hussein Abdallah, et al. / Proceedings of the Creative Construction Conference (2019) 095

https://doi.org/10.3311/CCC2019-095

[11] J. Arora, O. Elwakeil, A. Chahande and C. Hseih, "Global optimization methods for engineering applications: A review," Springer Link, vol. 9, no. 3-4, p. 137-159, 1995.

[12] MathWorks, "gamultiobj," MathWorks, 2018. [Online]. Available: https://www.mathworks.com/help/gads/gamultiobj.html.

[13] U. B. University, Optimization Toolbox, Berkely: ic design classes.

[14] C. S. University, Constrained Optimization using MATLAB's fmincon, Colorado: Mathematics Department.

[15] H. S. Park, B. Kwon, Y. Shin, Y. Kim, T. Hong and S. W. Choi "Cost and CO2 Emission optimization of Steel Reinforced Concrete Columns in High-Rise Buildings," Energies, no. 6, pp. 5609-5624, 2013. https://doi.org/10.3390/en6115609

[16] C. V. Camp, S. Pezeshk and H. Hansson, "Flexural Design of Reinforced Concrete Frames Using a Genetic Algorithm," Journal of Structural Engineering, vol. 1, no. 129, pp. 105-115, 2003. https://doi.org/10.1061/(ASCE)0733-9445(2003)129:1(105)

[17] M. Molitch-Hou, "FROM CARBON TO CONCRETE: POLLUTION CONVERTED INTO 3D PRINTING FEEDSTOCK FOR CONSTRUCTION," 3D Printing Industry, March 2016. [Online]. Available: https://3dprintingindustry.com/news/from-carbon-to-concretepollution-converted-into-3d-printing-stock-73747/. [Accessed April 2018].

[18] El Sakka F. (S) \& Hamzeh, F.R, 2017, '3d Concrete Printing in the Service of Lean Construction.' In: 25th Annual Conference of the International Group for Lean Construction. Heraklion, Greece, 9-12 Jul 2017. Pp 781-788 https://doi.org/10.24928/2017/0246 